\title{
When Can Herbivores Slow or Reverse the Spread of an Invading Plant? A Test Case from Mount St. Helens
}

\author{
William F. Fagan, ${ }^{1}$ Mark Lewis, ${ }^{2}$ Michael G. Neubert, ${ }^{3}$ Craig Aumann, ${ }^{1}$ Jennifer L. Apple, ${ }^{4}$ and John G. Bishop ${ }^{4}$
}

1. Department of Biology, University of Maryland, College Park, Maryland 20742;

2. Departments of Biological Sciences and Mathematical and Statistical Sciences, University of Alberta, Edmonton, Alberta T6G 2E1, Canada;

3. Biology Department, Woods Hole Oceanographic Institution, Woods Hole, Massachusetts 02543;

4. School of Biological Science, Washington State University, Vancouver, Washington 98686

Submitted February 1, 2005; Accepted July 26, 2005;

Electronically published October 4, 2005

Online enhancements: appendixes.

ABSTRACT: Here we study the spatial dynamics of a coinvading consumer-resource pair. We present a theoretical treatment with extensive empirical data from a long-studied field system in which native herbivorous insects attack a population of lupine plants recolonizing a primary successional landscape created by the 1980 volcanic eruption of Mount St. Helens. Using detailed data on the life history and interaction strengths of the lupine and one of its herbivores, we develop a system of integrodifference equations to study plant-herbivore invasion dynamics. Our analyses yield several new insights into the spatial dynamics of coinvasions. In particular, we demonstrate that aspects of plant population growth and the intensity of herbivory under low-density conditions can determine whether the plant population spreads across a landscape or is prevented from doing so by the herbivore. In addition, we characterize the existence of threshold levels of spatial extent and/or temporal advantage for the plant that together define critical values of "invasion momentum," beyond which herbivores are unable to reverse a plant invasion. We conclude by discussing the implications of our findings for successional dynamics and the use of biological control agents to limit the spread of pest species.

Keywords: biocontrol, Filatima, integrodifference equation model, Lupinus lepidus, primary succession, spatial spread.

Am. Nat. 2005. Vol. 166, pp. 669-685. (c) 2005 by The University of Chicago. 0003-0147/2005/16606-40873\$15.00. All rights reserved.
The spatial spread of invading species has been the subject of extensive ecological research since Skellam (1951) applied Fisher's (1937) model of gene flow to characterize the "wave of advance" of an invading species. Invasion dynamics warrant such attention because understanding how species spread spatially is of tremendous practical importance. Whether in characterizing risks from expanding pest species (Hajek et al. 1996; Sharov et al. 2002), understanding the success or failure of biological control agents (Louda et al. 1997; Fagan et al. 2002), or predicting the resurgence of native species reintroduced within their historical ranges (Lubina and Levin 1988; Lensink 1997; Caswell et al. 2003), understanding the dynamics of spatial spread has proved important in many areas of applied ecology.

Since Skellam's initial effort, empiricists and theoreticians have demonstrated that biological invasions are considerably more complex than Skellam's single-species deterministic model suggests. Characteristics of invading species, such as density dependence (Veit and Lewis 1996) and life history (van den Bosch et al. 1990; Neubert and Caswell 2000), and characteristics of the environments through which invasions are occurring, such as landscape heterogeneity (Shigesada et al. 1986; Andow et al. 1990) and temporal stochasticity (Neubert et al. 2000), have received attention by ecologists. In addition, theoretical attention to the "dispersal kernels" that characterize the probability of individuals dispersing particular distances has identified the importance of long-distance dispersal to the velocity of spatial spread of an invading species (Kot et al. 1996; Clark et al. 1998; Caswell et al. 2003).

Species interactions can mediate the spatial dynamics of invading species. For example, studying two species of squirrels in Britain, Okubo et al. (1989) demonstrated how invasion models could be used to understand the spatial displacement of one species by a competitor. Parker (2000) and Parker and Haubensak (2002) demonstrated the potential for mutualistic pollinator species to influence invasion success of nonnative shrubs and established that such influences can be strongly context dependent. Dunbar (1983) modeled the dynamics of a consumer invading 
a resource species at equilibrium, and Sherratt et al. (1995) explored how coinvading predator and prey species can generate spatiotemporal chaos in the invasion's wake. Petrovskii et al. (2002) studied how predator-prey interactions in concert with Allee effects can generate "patchy" invasions, where the distribution of invasive species across a landscape is heterogeneous in both time and space.

Working with a two-species partial differential equation model, Owen and Lewis (2001) provided the first analysis of conditions under which a coinvading consumer can alter the velocity of spatial advance of a resource species. For that model, only under very stringent conditions can the consumer actually reverse an invasion by a resource species. In particular, for reversal to occur, the resource species must possess a strong Allee effect such that its population growth rate is negative at low densities (Owen and Lewis 2001).

Here we expand on the general theoretical efforts of Owen and Lewis (2001) to study the spatial dynamics of a specific, empirically motivated case of coinvasion by a consumer-resource pair recolonizing a primary successional landscape. Using detailed data on the life history and interaction strengths of a lupine plant and one of its herbivores, we develop a system of integrodifference equations to study plant-herbivore invasion dynamics. We demonstrate that the intensity of herbivory under lowdensity conditions can determine whether the plant population spreads across a landscape or is prevented from doing so by the herbivore. In addition, we characterize the existence of threshold levels of spatial extent and/or temporal advantage for the plant that together define critical values of "invasion momentum," beyond which herbivores are unable to reverse a plant invasion. We conclude by discussing the implications of our findings for successional dynamics and the use of biological control agents.

\section{Overview of the Field System}

The 1980 eruption of Mount St. Helens (Washington) began with the largest landslide in recorded history, which was followed by a devastating lateral volcanic blast, pyroclastic flows, and lahars that together created $60 \mathrm{~km}^{2}$ of primary successional habitat referred to as the "pumice plain and debris avalanche" (hereafter "pumice plain"). Since first colonizing the pumice plain in 1981 (Wood and del Moral 1987), the prairie lupine Lupinus lepidus var. lobbii, a native nitrogen-fixing legume, has spread across this landscape. The interactions between this plant and its associated specialist herbivores afford a unique opportunity to study the effects of consumer-resource dynamics on primary succession. Contrary to the prevailing view that insects have little influence on primary succession (e.g., McCook 1994; Walker and del Moral 2003), large- scale demographic studies (Bishop and Schemske 1998; Bishop 2002; Bishop et al. 2005) and small-scale removal experiments (Fagan and Bishop 2000) demonstrate that insect herbivory has strongly affected the abundance, demography, and spatial structure of colonizing prairie lupines.

Like many invading species (Mack 1981; Petrovskii et al. 2002; Sharov et al. 2002), the lupine population exhibits a patchy spatial structure. Patches within the "edge" region are small (less than a few tens of meters in diameter) and young and are located $0.2-3 \mathrm{~km}$ from the position of the initial 1981 colonization event. Edge patches possess less than $15 \%$ lupine cover and are separated by a matrix of mostly bare rock featuring very low lupine densities (typically far less than 1 plant $\mathrm{m}^{-2}$, with less than $1 \%$ cover). Edge patches are often short-lived and exhibit a high turnover rate (del Moral 2000a, 2000b). On the other hand, in "core" regions, where lupine densities are far higher (hundreds to more than a thousand plants per square meter, with more than $20 \%$ cover from lupines) and patches are hundreds of meters in diameter and more than a decade old (Fagan and Bishop 2000; Bishop 2002; Fagan et al. 2004; Bishop et al. 2005). Although the patchy nature of recolonization and bursts of lupine recruitment mean that there is not really a distinct border between core and edge regions, edge and core regions provide a conspicuous visual contrast.

Several lepidopteran species feed on lupines and can inflict severe damage. Such herbivory has occurred for more than a decade (fig. 1; Fagan and Bishop 2000; Bishop et al. 2005) and exhibits striking inverse density dependence. High densities of lepidopterans and their associated damage are consistently restricted to areas of low lupine density, specifically edge areas and the outer margins of core patches (Fagan et al. 2004). The identity of herbivoreaffected patches shifts over time in a spatial mosaic as lupine patches form, grow, and fail.

Evidence suggests that top-down and bottom-up mechanisms may interact synergistically to produce this inverse density-dependent herbivory (Fagan and Bishop 2000; Fagan et al. 2004; Bishop et al. 2005). Our focus here, however, is on the dynamic consequences of this density dependence rather than its specific mechanism. By inducing net negative population growth at the fringes of the expanding lupine population, intense herbivory confined to the edge region reduces the rate of spatial spread for lupine (Fagan and Bishop 2000) and increases patch turnover (del Moral 2000a, 2000b). In some locations, we have even observed patch "shrinkage" due to intense herbivory at patch edges that suppresses lupine recruitment (Bishop et al. 2005). Because lupines make diverse and important contributions to the mechanics of local primary succession at Mount St. Helens (Kerle 1985; Titus and del Moral 1998; 


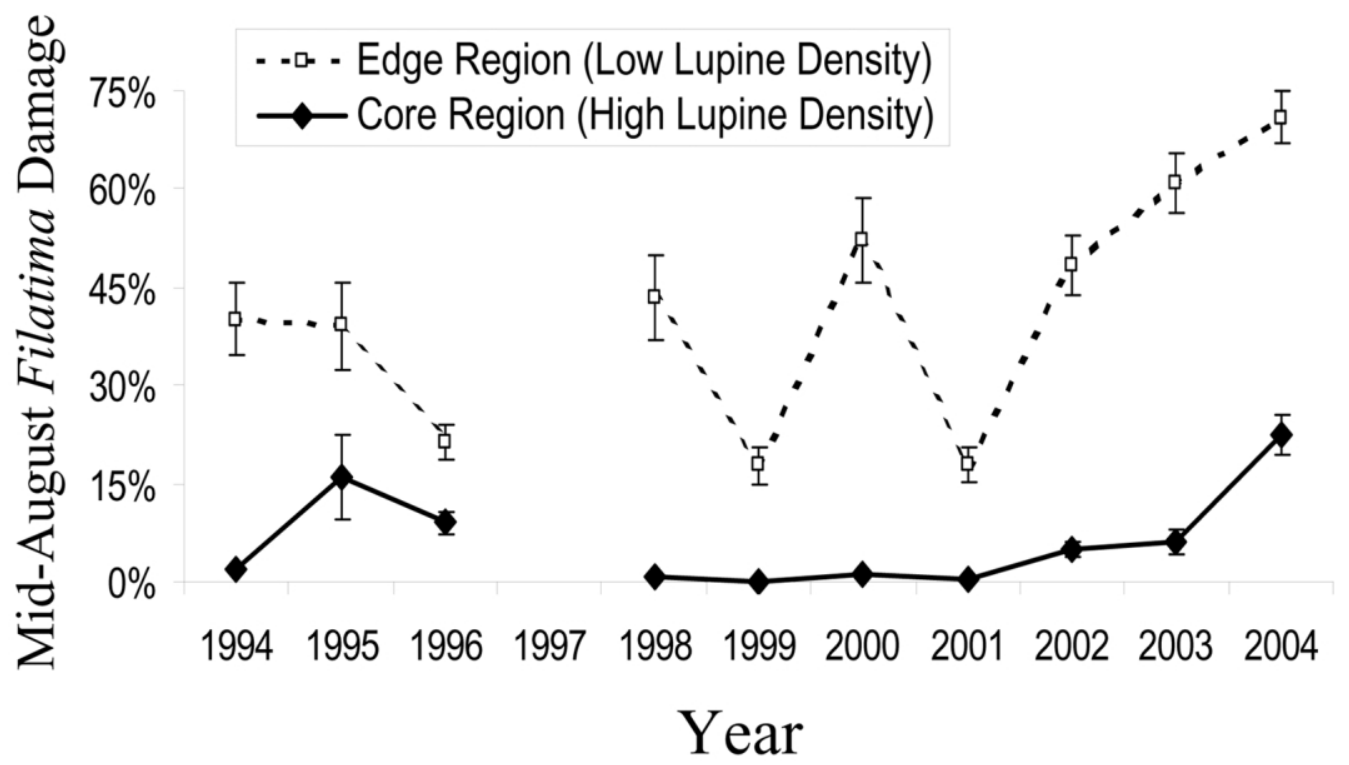

Figure 1: Mean $( \pm$ SE) percentage of leaf surface area destroyed by Filatima leaf-tying caterpillars by mid-August over the years 1993-2003. Lowdensity edge sites ( $\leq 8$ years old, $<15 \%$ lupine cover) and high-density core sites ( $\geq 10$ years old, $>20 \%$ lupine cover) exhibit strong contrasts in lupine patch characteristics. Different sites were censused in different years to maintain consistency of patch characteristics even as individual lupine patches aged, became denser, or were eliminated by herbivores or erosion.

Morris and Wood 1989; Halvorson et al. 1991, 1992; Halvorson and Smith 1995; del Moral and Rozzell, forthcoming), herbivores that affect lupine distribution may be influencing successional processes.

To understand how herbivory influences the landscapescale distribution of lupine, we developed a model of the interaction between lupine and one of its most important herbivore guilds, leaf-tying caterpillars. Two very similar species, one a gelechiid moth, Filatima sp., the other a pyralid moth, Staudingeria albipenella, specialize on L. lep$i d u s$. Because the bulk of our empirical data derive from studies of Filatima, we focus on that species as we develop a model of the plant-herbivore coinvasion process. Caterpillars of both moth species are "leaf tiers" that bind lupine leaves together into small webbed structures to feed, leaving behind conspicuous whitish-yellow woven masses (fig. 1; Bishop 2002; plate 1 in Fagan et al. 2004). By destroying lupine vegetative tissues, leaf tiers can reduce lupine seed set by as much as an order of magnitude (Fagan and Bishop 2000; Bishop 2002). Thus, Filatima herbivory principally affects the lupine population through reduced recruitment rather than outright mortality of plants. Decreases in seed production induced by Filatima then act synergistically with damage by other herbivore guilds (e.g., root borers, cutworms, seed predators) to limit lupine population growth rate (Fagan and Bishop 2000; Bishop 2002). In Fagan and Bishop (2000), damage from
Filatima and Staudingeria was mistakenly attributed to Euxoa extranea, another important foliage feeder on prairie lupine at Mount St. Helens.

\section{Phenology of the Lupine-Filatima Interaction}

At Mount St. Helens, Lupinus lepidus is perennial, with an average life span of 4 years and a short-lived seed bank (Bishop 1996, 2002). Seed germination occurs in late spring, at the beginning of a growing season that lasts about 3.5 months. Under good conditions, lupines can reproduce in their first growing season. Dehiscence of lupine fruits and initial dispersal of lupine seeds occurs in early fall. Subsequent seed dispersal may occur as a result of animal dispersal (e.g., voles), winter runoff, and high winds. In contrast, redistribution of the leaf tier populations takes place in June, at which time moths are flying and ovipositing. Feeding on lupine leaves, larvae grow through several instars before entering diapause in the fall. To model the interaction, we collapse the above phenology into two stages (fig. 2). Stage I, the redistribution stage, encompasses fall seed dispersal of lupines, spring dispersal by Filatima moths, and overwinter mortality of both species. Stage II, the consumption and growth stage, deals with the dynamics of both species during the growing season, which we define as June 15 to August 31. 


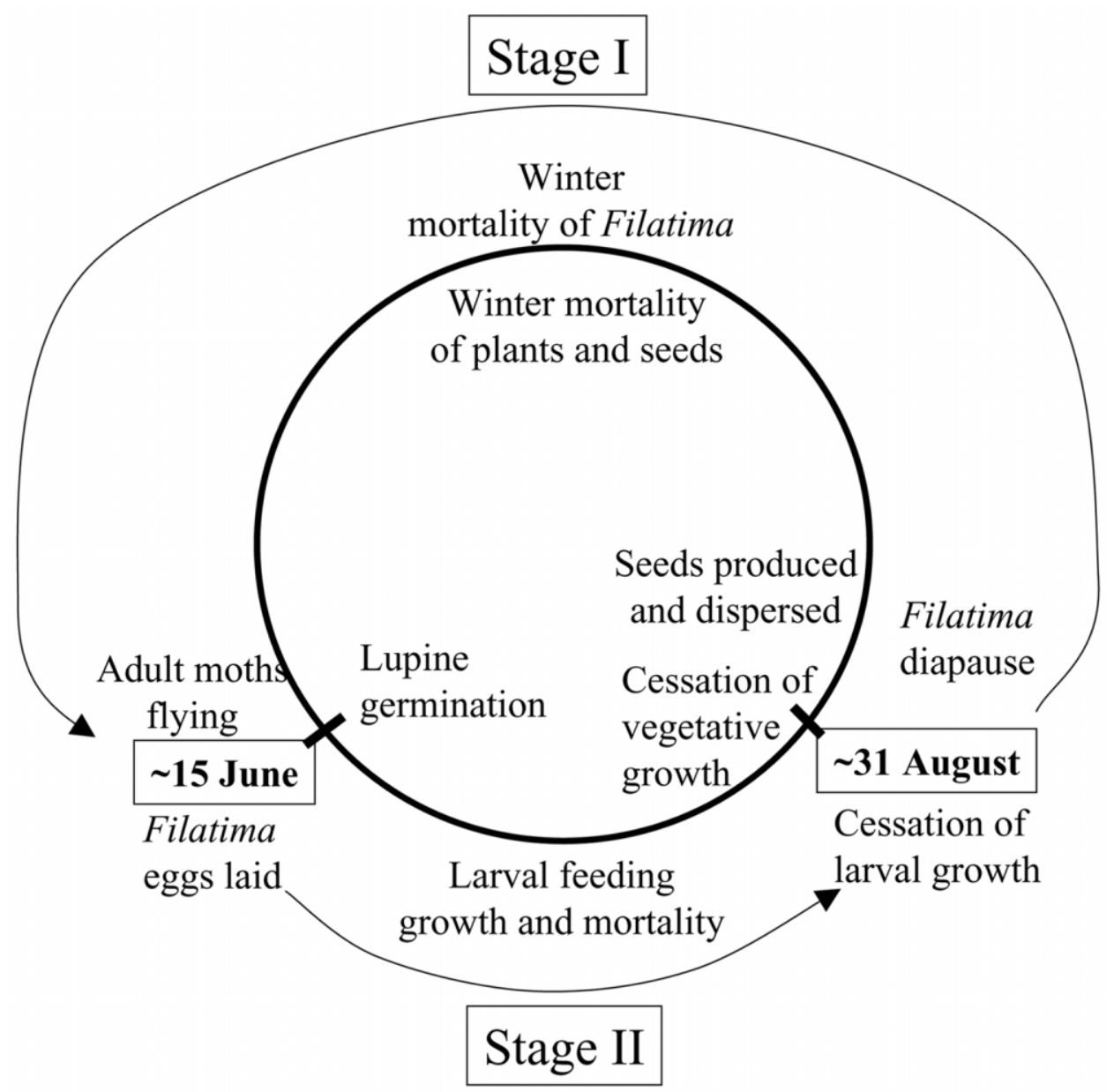

Figure 2: Life cycle and phenology of Lupinus and Filatima. Breakpoints between the winter season (stage I of the model) and the growing season (stage II) are approximate.

\section{An Integrodifference Model of Consumer-Resource Invasion Dynamics}

To match both the perennial life history of Lupinus lepidus and the univoltine life cycle of the leaf tiers, we developed a model that possessed a tripartite stage structure for the lupines (seed/seedling/adult) but modeled explicitly only the larval stage of the herbivores. To take full advantage of long-term spatial data on the lupine-leaf tier interaction, including data collected by other researchers for other purposes, we adopt the somewhat unconventional practice of modeling plant-herbivore dynamics via a mixture of "proportion cover" for adult plants and herbivore damage (i.e., a rescaling of plant ecologists' traditional "percent cover" measure) and densities for seeds and seedlings. We model the spatial dynamics of herbivores and plants in one spatial dimension, denoting position by $x(\mathrm{~cm})$ and time by $t$ (years). Our four state variables are $p_{t}(x)$, a dimensionless measure defined as the proportion of the surface of a site covered by undamaged plants; $s_{t}(x)$, the lupine seed density $\left(\mathrm{cm}^{-1}\right) ; j_{t}(x)$, the lupine seedling density $\left(\mathrm{cm}^{-1}\right)$; and $l_{t}(x)$, the density of larval leaf tiers $\left(\mathrm{cm}^{-1}\right)$.

We use integrodifference equations (e.g., Kot et al. 1996) to model dispersal of lupine seeds and, via assumptions about moth dispersal and oviposition, the redistribution of the next generation of feeding caterpillars. Integrodifference equations take the general form

$$
N_{t+1}(x)=\int k(x-y) f\left(N_{t}(y)\right) d y,
$$

where $N$ is the density of a species, $f(N(y))$ is a function describing the recruitment of the species at position $y$, and $k(x-y)$ is a "redistribution kernel" defining how individuals produced at positions $y$ get redistributed to position 
$x$. These kernels can take a wide variety of shapes (Neubert et al. 1995), but in the context of spatially spreading populations, particular interest is focused on kernels with broad tails that allow for long-distance dispersal. Although long-distance dispersal occurs occasionally in lupines (e.g., the first recolonizing lupine seed is estimated to have dispersed more than $2 \mathrm{~km}$ from the nearest seed source; Bishop et al. 2005), long-distance dispersal appears to be far more frequent among herbivores. Adult Filatima moths are weak and reluctant fliers, but if they are disturbed and if they then manage to ascend through the boundary layer near the ground surface, wind currents can carry them many tens of meters in just a few seconds. When windblown, these $\sim 6$-mm-long moths routinely outpace field crews attempting to track their long-distance movements. In contrast, redistribution of feeding caterpillars is highly localized and is negligible on the scale of the pumice plain. Lacking detailed data on the dispersal of either the plant or the herbivores, we assume that the lupines and the leaf tiers each have Laplace dispersal kernels. Thus, for the plants,

$$
k_{\mathrm{p}}(x-y)=\frac{\alpha}{2} e^{-\alpha|x-y|},
$$

where $\alpha\left(\mathrm{cm}^{-1}\right)$ is the reciprocal of the mean seed dispersal distance. Likewise, for the moths,

$$
k_{\mathrm{m}}(x-y)=\frac{\beta}{2} e^{-\beta|x-y|},
$$

where $\beta\left(\mathrm{cm}^{-1}\right)$ is the reciprocal of the mean moth dispersal distance. These functional forms are consistent with a diffusive form of one-dimensional dispersal in which there is a constant probability per unit time of settling (Broadbent and Kendall 1953; Neubert et al. 1995). (See app. A in the online edition of the American Naturalist for a brief discussion of dimensionality and invasion dynamics.) The kernel $k$ then describes the expected locations of settled individuals that started at point $y$.

\section{Stage I: Overwinter Dynamics}

During stage I (see fig. 2), four different aspects of the plant herbivore dynamics occur between time $t$ and the end of the stage, denoted $\tau$. First, lupine seed production is determined by local conditions set by plant crowding (as measured by proportion cover) and the density of Filatima caterpillars, both measured at the end of the preceding growing season. As mentioned above, one of $\mathrm{Fi}$ latima's most important effects on lupine demography is a major reduction in seed output in patches with extensive herbivory (Fagan and Bishop 2000; Bishop 2002). We rep- resent this effect on seed production at location $y$ by discrete-time host-resource dynamics,

$$
f_{\mathrm{p}}\left(p_{t}(y), l_{t}(y)\right)=b_{0} p_{t}(y) e^{-b_{1} l_{t}(y)}
$$

(Hassell 1978), where $b_{0}$ is the seed density produced at $100 \%$ lupine cover in the absence of Filatima larvae and $b_{1}$ determines how steeply the density of lupine seeds produced decays with increases in herbivore density (Bishop 2002).

Seeds produced in a given year are redistributed according to a dispersal kernel $k_{\mathrm{p}}$ from equation (2). We assume that after this initial redistribution, seeds do not disperse any further (e.g., seeds in the seed bank remain in place). A fraction $\sigma_{\mathrm{s}}$ of all seeds survive the winter. A fraction $\gamma$ of the surviving just-dispersed seeds and an equal fraction of the surviving seed bank seeds germinate in late spring. Thus, the combined effects of seed production, redistribution, mortality, and germination yield the seedling density at the start of the growing season,

$$
j_{t+\tau}(x)=\sigma_{s} v\left[\int k_{p}(x-y) f_{p}\left(p_{t}(y), l_{t}(y)\right) d y+s_{t}(x)\right] .
$$

Second, seeds that do not germinate, excluding the fraction $\left(1-\sigma_{\mathrm{s}}\right)$ that die during the winter, enter the seed bank, yielding

$$
\begin{aligned}
s_{t+\tau}(x)= & \sigma_{\mathrm{s}}(1-\gamma) \\
& \times\left[\int k_{\mathrm{p}}(x-y) f_{\mathrm{p}}\left(p_{t}(y), l_{t}(y)\right) d y+s_{t}(x)\right] .
\end{aligned}
$$

Third, lupine plants existing at the end of the preceding growing season also suffer overwinter mortality, which reduces the undamaged proportion cover by a factor $\sigma_{\mathrm{p}}$, yielding

$$
p_{t+\tau}(x)=\sigma_{\mathrm{p}} p_{t}(x) .
$$

Fourth, Filatima moths are produced in proportion to the local larval density at the end of the preceding growing season, scaled by the fraction of larvae that survive diapause $\left(\sigma_{1}\right)$. To simplify the modeling, we assume that oviposition by Filatima moths depends on the proportion lupine cover that was present at a particular site at the end of the preceding growing season. This assumption matches recent discoveries about the moths' biology. Filatima females lay eggs in leaf axils as lupine leaves are flushing out in spring. Lupine cover in spring and fall are highly correlated because these leaf tiers cause little direct lupine mortality and instead affect the lupine population through reduction of seed set (Fagan 
and Bishop 2000; Bishop 2002). We further assume that the density of lupine seedlings (which do not contribute to proportion cover) has no effect on Filatima oviposition. Nevertheless, Filatima caterpillars do routinely consume leaves from seedlings, but rather than deal with this issue here, we attend to it during development of stage II of the model. These assumptions, together with the redistribution kernel for the herbivores, $k_{\mathrm{m}}$ in equation (3), yield the moth density as

$$
\int k_{\mathrm{m}}(x-y) p_{t}(y) \sigma_{1} l_{t}(y) d y .
$$

We extract $\sigma_{1}$ from the integral and multiply it by per capita female fecundity of the moths $\left(f_{\mathrm{m}} / 2\right.$, assuming a $1: 1$ sex ratio) and the proportion of eggs that successfully hatch into caterpillars $\left(\sigma_{\mathrm{e}}\right)$ into the composite parameter $\theta$ representing the per larva recruitment to the next generation. We then write the larval density at the beginning of the next growing season as

$$
l_{t+\tau}(x)=\theta \int k_{\mathrm{m}}(x-y) p_{t}(y) l_{t}(y) d y .
$$

\section{Stage II: Growing Season Dynamics}

Lupine growth and herbivore feeding and growth take place concurrently during stage II between times $t+\tau$ and $t+1$ (fig. 2). To model these processes, we adopted an approach that subdivides stage II into two steps (one for plant growth and one for herbivory). In the first step, we assume that lupine plants undergo a season's worth of growth free from herbivory and are limited only by their own ability to fill space (i.e., plants are limited by the imposition of a maximum proportion cover of 1.0). Growth of established lupine plants is thus determined by the saturating Beverton-Holt function

$$
B\left(p_{t+\tau}, T\right)=\frac{p_{t+\tau} e^{r T}}{p_{t+\tau}\left(e^{r T}-1\right)+1}
$$

(Kot 2001), where $r\left(\right.$ day $\left.^{-1}\right)$ is the vegetative growth rate of plants and $T$ (days) is the duration of the growing season. Because under crowded conditions established plants have growth advantages over seedlings (Harper 1977; Silvertown and Lovett-Doust 1993), we give growth priority to established plants such that seedlings can, at most, grow to fill only that fraction of space not already filled by established plants or the growth of those plants during the growing season. Lupine growth is assumed to occur before any herbivory occurs, such that at the end of the first step of stage II, undamaged lupine cover (denoted by the temporary variable $p^{*}$ ) can be written

$$
p^{*}=B\left(p_{t+\tau}, T\right)+\min \left\{1-B\left(p_{t+\tau}, T\right), g j_{t+\tau}\right\},
$$

where $g$ is the average end-of-season size of lupine seedlings and the minimum function is used to give growth priority to established plants. Having the plants grow first, before any herbivory, may seem unduly advantageous to the caterpillars. However, because herbivore mortality increases with plant cover in the model (see eq. [12]), the "plants-first" simplification actually underestimates the effects of herbivores in the system.

Herbivory by Filatima larvae occurs during the second step of stage II. To match available field data and protocols, we do not model changes in larval density explicitly but instead model larval dynamics indirectly, via changes in proportion lupine cover. The proportion of lupine cover damaged by Filatima larvae at the end of the growing season $(F)$ depends on both lupine cover and larval density and is represented by the saturating feeding function

$$
F\left(p^{*}, l_{t+\tau}\right)=\frac{p^{*} l_{t+\tau}}{\left(p^{*} / a\right)+l_{t+\tau}},
$$

where $a\left(\mathrm{~cm}^{2}\right)$ is a parameter defining how damaged cover saturates relative to increases in lupine cover and larval density. Damaged lupine cover is converted back to larval densities at rate $\mu_{0}+\mu_{1} p^{*}$, where $\mu_{0}\left(\right.$ day $\left.^{-1}\right)$ is the rate of "background" larval mortality and $\mu_{1}\left(\right.$ day $\left.^{-1}\right)$ is an additional mortality rate associated with increased lupine cover. Hence, the amount of damaged lupine cover converted back to larval densities in time $T$ is

$$
\phi\left(p^{*}, T\right)=c e^{-\left(\mu_{0}+\mu_{1} p^{*}\right) T},
$$

where $c$ is the number of caterpillars produced per square centimeter of lupine eaten.

The structure of equation (12), in which the larval mortality rate increases in proportion to lupine cover, is critical to the dynamics of our model. It establishes a mechanism by which larval performance is enhanced under low-cover conditions like those of the edge region at Mount St. Helens. We identified the existence of this dependence of Filatima mortality on lupine density in laboratory growth studies of caterpillars (Fagan et al. 2004) and have since found that the mortality is linked to both decreased nutrient content and increased induction of toxic alkaloids (specifically, ammodendrine) in lupine plants growing under high-density conditions (J. G. Bishop, J. Apple, M. Wink, and W. F. Fagan, unpublished data). By combining the conversion function with the caterpillar feeding func- 
tion, we can write the density of larvae at the end of the growing season as

$$
l_{t+1}=\phi\left(p^{*}, T\right) F\left(p^{*}, l_{t+\tau}\right) .
$$

Having determined how much damage the caterpillars would cause, we can update lupine cover from step 1 to the end of the growing season using

$$
p_{t+1}=p^{*}-F\left(p^{*}, l_{t+\tau}\right) .
$$

Finally, we assume no mortality of seeds in the seed bank during the growing season, giving

$$
s_{t+1}=s_{t+\tau} .
$$

In summary, our final system of equations thus becomes

$$
\begin{aligned}
& p_{t+\tau}(x)=\sigma_{\mathrm{p}} p_{t}(x), \\
& j_{t+\tau}(x)=\sigma_{\mathrm{s}} \gamma\left[\int k_{\mathrm{p}}(x-y) f_{\mathrm{p}}\left(p_{t}(y), l_{t}(y)\right) d y+s_{t}(x)\right], \\
& s_{t+\tau}(x)=\sigma_{\mathrm{s}}(1-\gamma)\left[\int k_{\mathrm{p}}(x-y) f_{\mathrm{p}}\left(p_{t}(y), l_{t}(y)\right) d y+s_{t}(x)\right], \\
& l_{t+\tau}(x)=\theta \int k_{\mathrm{m}}(x-y) p_{t}(y) l_{t}(y) d y
\end{aligned}
$$

for stage I and

$$
\begin{aligned}
p^{*}(x) & =B\left(p_{t+\tau}(x), T\right)+\min \left\{1-B\left(p_{t+\tau}(x), T\right), g j_{t+\tau}(x)\right\}, \\
l_{t+1}(x) & =\phi\left(p_{t+\tau}(x), T\right) F\left(p^{*}(x), l_{t+\tau}(x)\right), \\
s_{t+1}(x) & =s_{t+\tau}(x) \\
p_{t+1}(x) & =p^{*}(x)-F\left(p^{*}(x), l_{t+\tau}(x)\right)
\end{aligned}
$$

for stage II. Initial conditions for this system were a localized (100-m radius) lupine colonization event, followed several years later by moth colonization. In all numerical solutions, the initial moth colonization was confined to the same 100-m-radius site that was the source of the lupine colonization. (This strategy accords with the actual invasion dynamics that occurred at Mount St. Helens, where, perhaps because of topographic effects on wind currents and the deposition of airborne particles [including insects; Edwards and Sugg 1993], the core region was the site of several "first introductions." Naturally, if we allowed the moths to colonize throughout the lupine pop- ulation immediately upon arrival, the dynamics would be different and the advantage would tend to shift to the herbivore.) We use the parameter $t_{0}$ (years) to control the duration of the time lag between the start of the plant and herbivore invasions. Using parameter estimates discussed in the next section, we solved equations (16) numerically in Matlab until $t=250$ years on a linear domain scaled to represent $50 \mathrm{~km}$ of invasible space. Thus, the lower and upper limits of integration for all of the integrals in equations (16) are 0 and $50 \mathrm{~km}$; this domain was effectively unbounded with respect to the parameter conditions we considered. For computational stability, we used 8,192 (i.e., $2^{13}$ ) computational nodes and assumed that if the maximum lupine percent cover $(p)$ fell below 0.000001, then both species became extinct.

\section{Parameterizing the Lupine-Filatima Model}

The full model in equations (16) involves 18 parameters, which are summarized in table 1 . We could estimate 14 of the parameters from a combination of field surveys, field experiments, and laboratory experiments, as discussed below. The four exceptions involved the dispersal parameters $(\alpha$ and $\beta$ ) and two parameters related to survivorship in the early life stages of Filatima $\left(\sigma_{1}\right.$ and $\left.\sigma_{\mathrm{e}}\right)$. We treated these exceptions as follows.

Because we lacked detailed information on dispersal of lupine seeds and ovipositing Filatima moths but believed moths to disperse farther on average than lupine seeds, we set the distance decay parameter for the seeds steeper than that for the moths. We used $\alpha=0.0035\left(\mathrm{~cm}^{-1}\right)$ for the seeds and $\beta=0.0005\left(\mathrm{~cm}^{-1}\right)$ for the moths. These parameter values convert into mean dispersal distances of $\sim 2.9$ and $20 \mathrm{~m}$ for the lupines and moths, respectively. (See "Discussion" for more information regarding these assumptions.) For the unknown larval parameters, we assumed $\sigma_{1}=0.75$ and $\sigma_{\mathrm{e}}=1$, implying that larval mortality does occur during the winter but that all eggs laid successfully hatch into larvae. Data from a related gelechiid moth species, Chionodes psiloptera, from eastern Washington, give $\sigma_{\mathrm{e}}>0.9$ (Oetting 1977). Because $\sigma_{1}$ and $\sigma_{\mathrm{e}}$ enter the same composite parameter ( $\theta$ in eq. [8]), we are left with three parameters that did not have direct empirical support $(\theta, \alpha$, and $\beta)$.

We established the beginning and end of the growing season as June 15 and August 31, respectively, as approximations for the dynamics witnessed over the last decade at Mount St. Helens. These choices yield $\tau=$ June 15 and $T=75$ days. Remaining parameters were estimable from empirical data or the literature. For example, the parameters $b_{0}$ and $b_{1}$, which together determine lupine seed production as functions of undamaged lupine cover and $\mathrm{Fi}$ latima larval density (eq. [4]), were obtained by nonlinear 
Table 1: Model parameters with definitions, dimensions, estimated values, and sources

\begin{tabular}{|c|c|c|c|}
\hline Parameter & Definition & Estimate & Data source \\
\hline$\overline{f_{\mathrm{m}} \text { (eggs per female) }}$ & Fecundity & Range: $30-147$ & $\begin{array}{l}\text { Oetting 1977; J. Apple } \\
\text { and J. G. Bishop, } \\
\text { unpublished data }\end{array}$ \\
\hline$\sigma_{1}$ & Overwinter larval survival & Guess: .75 & \\
\hline$\sigma_{\mathrm{e}}$ & Egg hatching success rate & Guess: 1 & \\
\hline$\theta$ (larvae per female) & $\begin{array}{l}\text { Product of moth fecundity and egg and } \\
\text { larval survivorship }\left(f_{\mathrm{m}} \sigma_{\mathrm{e}} \sigma_{\mathrm{l}} / 2\right)\end{array}$ & Calculated & \\
\hline$c\left(\mathrm{~cm}^{-2} ;\right.$ mean $\left.\pm \mathrm{SE}\right)$ & $\begin{array}{l}\text { Number of caterpillars produced per } \mathrm{cm}^{2} \text { of } \\
\text { plant eaten }\end{array}$ & $.42 \pm .04$ & Fagan et al. 2004 \\
\hline$\mu_{0}\left(\right.$ day $\left.^{-1}\right)$ & $\begin{array}{l}\text { Mortality of larvae independent of percent } \\
\text { cover }\end{array}$ & Point estimate: .0086 & Fagan et al. 2004 \\
\hline$\mu_{1}\left(\right.$ day $\left.^{-1}\right)$ & $\begin{array}{l}\text { Mortality of larvae dependent on } \\
\text { undamaged percent cover }\end{array}$ & Point estimate: .054 & Fagan et al. 2004 \\
\hline$\phi\left(\mathrm{cm}^{-2}\right)$ & $\begin{array}{l}\text { Number of mature caterpillars produced at a } \\
\text { given level of plant cover }\left(c e^{-\left(\mu_{0}+\mu_{1} p_{t+\tau}\right) T}\right)\end{array}$ & Calculated & \\
\hline $\begin{array}{l}b_{0}\left(\mathrm{~cm}^{-2} ; \text { mean } \pm\right. \\
\mathrm{SE})\end{array}$ & $\begin{array}{l}\text { Seed density produced at } 100 \% \text { lupine cover } \\
\text { in the absence of herbivores }\end{array}$ & $.75 \pm .45$ & Bishop 2002 \\
\hline$b_{1}\left(\mathrm{~cm}^{2} ;\right.$ mean $\left.\pm \mathrm{SE}\right)$ & Decay of seed density with herbivore density & $139 \pm 95$ & Bishop 2002 \\
\hline$\sigma_{\mathrm{p}}$ & Overwinter plant survivorship & .80 ; range: $.75-.84$ & Bishop 2002 \\
\hline$\sigma_{\mathrm{s}}($ mean $\pm \mathrm{SE})$ & Seed survivorship & $.22 \pm .14$ & Bishop 1996 \\
\hline$\gamma($ mean $\pm S E)$ & Seed germination fraction & $.77 \pm .03$ & Bishop 1996 \\
\hline$r\left(\right.$ day $^{-1} ;$ mean $\left.\pm \mathrm{SE}\right)$ & Vegetative growth rate of plants & $\begin{array}{l}\text { Current: } .006_{-.002}^{+.004} \\
\text { historic: } .026_{-.004}^{+.006}\end{array}$ & $\begin{array}{l}\text { Fagan and Bishop 2000 } \\
\text { Bishop } 2002\end{array}$ \\
\hline$a\left(\mathrm{~cm}^{2} ;\right.$ mean $\left.\pm \mathrm{SE}\right)$ & Damage cover saturation variable & $2.09 \pm .33$ & Fagan and Bishop 2000 \\
\hline$g\left(\mathrm{~cm}^{2} ;\right.$ mean $\left.\pm \mathrm{SE}\right)$ & Average end-of-season size of seedlings & $2.98 \pm .17$ & Bishop 2002 \\
\hline$\alpha\left(\mathrm{cm}^{-1}\right)$ & Distance decay of lupine seed dispersal & .0035 & Fagan and Bishop 2000 \\
\hline$\beta\left(\mathrm{cm}^{-1}\right)$ & $\begin{array}{l}\text { Distance decay of dispersal by ovipositing } \\
\text { moths }\end{array}$ & .0005 & \\
\hline$T$ (days) & Duration of growing season & 75 & \\
\hline$\tau$ & Time of germination & June 15 & \\
\hline$t_{0}$ (years) & $\begin{array}{l}\text { Time lag between the start of the lupine and } \\
\text { Filatima invasions }\end{array}$ & 8 ; range: $5-12$ & $\begin{array}{l}\text { Bishop 1996; Bishop et } \\
\text { al. } 2005\end{array}$ \\
\hline
\end{tabular}

least squares fits of the function $f_{\mathrm{p}}(p, l)$ to a large demographic data set of lupine fecundity estimates (Bishop 1996, 2002; Bishop and Schemske 1998). For the purposes of this calculation, fecundity was determined at the level of the patch, not the plant, yielding 355 unique patch $\times$ year combinations spanning five field seasons. Seeds produced but subsequently destroyed by insect seed predators were excluded from the calculations. In 86 of the patch $\times$ year combinations, no seeds were produced; virtually all of these cases of reproductive failure involved patches with low lupine density but high Filatima density. The same long-term study yielded data on the fraction of seeds that successfully overwinter, the overwinter persistence of lupine proportion cover, and the fraction of seeds germinating, providing estimates for $\sigma_{\mathrm{s}}, \sigma_{\mathrm{p}}$, and $\gamma$, respectively (Bishop 1996, 2002).

The estimate of per capita fecundity of female Filatima moths, $f_{\mathrm{m}}=30$, was obtained from field-caught females that were enclosed in chambers with potted plants on which to oviposit. Data from a related species, Chionodes psiloptera, suggest that egg laying in this group of moths may actually be a multiday, multi-eggmass process (Oetting 1977), and therefore our data may be a substantial underestimate because we did not know the age and oviposition history of our field-caught females. For Chionodes psiloptera, per capita fecundity was 147 (range 126-184). Note, however, that uncertainty in this parameter is subsumed in the composite parameter $\theta$, which is already "tunable" because we lack estimates for its other components (eq. [8]).

Multiple methods are available for estimating the vegetative growth rate of lupine (eq. [9]). One approach is to calculate $r=\ln \left(\mathrm{SA}_{\mathrm{E}} / \mathrm{SA}_{\mathrm{B}}\right) / T$, where $\mathrm{SA}_{\mathrm{B}}$ and $\mathrm{SA}_{\mathrm{E}}$ represent lupine surface area at the beginning and end of the growing season, respectively. Making this calculation using data from low-density lupine patches to which a broadspectrum insecticide had been applied at the beginning of the 1995 season yields an upper estimate of $r=0.026$ 
$\left(\right.$ day $^{-1}$; Fagan and Bishop 2000). More recent data from repeated transect surveys for regions where Filatima are absent but other herbivores (e.g., Hystricophora root borers, Euxoa folivores) are present yield a substantially lower estimate of lupine growth potential, $r=0.006\left(\right.$ day $\left.^{-1}\right)$. Both of these estimates are lower than the very high rates of lupine population growth recorded in the first few years after the eruption $\left(r=0.033\right.$ [day $\left.^{-1}\right]$; in other words, the population multiplier $\lambda>11$ [year $^{-1}$ ]; Fagan and Bishop 2000; Bishop et al. 2005).

The parameter $g$, which is needed to convert lupine seedling density to proportion cover (eq. [10]), was estimated from demographic studies of 2,144 marked plants that were seedlings at the beginning of a growing season and were followed through to the end of that growing season. The average size includes the effects of plants that died and was estimated as a single value across all plots and years, thus ignoring effects of local density. We estimate $g=2.98\left(\mathrm{~cm}^{2}\right)$.

To estimate $a$, which controls how quickly Filatima damage saturates with proportion lupine cover and larval density, we fitted equation (11) via nonlinear least squares to data from a field experiment that used an insecticide to manipulate larval density across a gradient in proportion lupine cover (Fagan and Bishop 2000). We estimate $a=2.09\left(\mathrm{~cm}^{2}\right)$.

We have two approaches to obtaining the parameter $c$, which represents the number of mature caterpillars produced per square centimeter of lupine eaten. First, a survey of 101 lupine plants of varying sizes and infestation levels (conducted August 17, 2000) yielded a relationship between number of caterpillar retreats (the webbed tunnels) and damaged lupine surface area $\left(\mathrm{cm}^{2}\right)$. This indicated a value of 0.24 caterpillars $\mathrm{cm}^{-2}$ of damage. However, because of the way the parameter enters the term $\phi$ in equation (12), this number has to be discounted for caterpillar mortality over the previous 62 days of the growing season, yielding 0.42 caterpillars $\mathrm{cm}^{-2}$ of damage, the estimate in table 1 . Alternatively, given a weight at pupation, a surface areabiomass relationship for lupine, and an estimate of larval growth efficiency, we can calculate the mass of lupine needed for a larva to reach maturity. We know average pupation weight for Filatima from Mount St. Helens to be $22 \mathrm{mg}$, and we have a relationship for lupine leaf biomass as a function of surface area (for 52 plants from the edge region where tissue quality is high, $y=0.0753 x-2.0056, r^{2}=$ $0.91)$. However, growth efficiency had to be estimated from the literature. Filatima is a specialist caterpillar feeding on a forb. Data in Scriber and Feeny (1979) give an average of $24.3 \%$ efficiency for caterpillars in this feeding category (range 11.6\%-41.5\%). Although the data became available too late to be incorporated in our modeling for this article, we recently estimated gross growth efficiency (GGE) =
14\% (range 7\%-25\%) for Euxoa feeding on these plants (J. Apple and J. G. Bishop, unpublished data). These data together yield an estimate for $c$ of 0.83 caterpillars $\mathrm{cm}^{-2}$ (range 0.40-1.42 caterpillars $\mathrm{cm}^{-2}$ ). Thus, our estimate from the first approach is at the low end of the estimates from the second approach. Although GGE is known to decrease with decreasing plant nutrient content (e.g., poorly matched plant-herbivore stoichiometry; Elser et al. 2000), data in Fagan et al. (2004) and Bishop et al. (2005) suggest that stoichiometry of lupine leaves from the edge region is well matched to the metabolic demands of Filatima.

The background larval mortality rate $\left(\mu_{0}\right)$ and the additional larval mortality due to increases in lupine density ( $\mu_{1}$; eq. [12]) were estimated from a 14-day laboratory growth study (Fagan et al. 2004). The two parameters were estimated via simultaneously solving two equations describing differential survivorship of Filatima caterpillars reared consistently on lupine leaves from sites with different plant densities.

\section{Expansion or Retreat of the Lupine- Herbivore Coinvasion?}

The integrodifference equation system we use to model the lupine-Filatima interaction (eqq. [16]) can exhibit either spatial advance or spatial contraction of both species jointly, depending on the parameter combinations used (fig. 3). Our best estimates of the system's parameters (table 1) predict long-term expansion of the coinvasion (fig. $3 a$ ) at a rate of approximately $25 \mathrm{~m}_{\text {year }}{ }^{-1}$. However, as we detail below, herbivory by Filatima greatly slows the lupine's rate of spread relative to herbivore-free conditions and is sufficient to cause a short-lived spatial contraction of the invading species. Small changes away from our best estimates for any of several parameters are sufficient to cause qualitatively different behavior in which the lupine and herbivore populations both collapse spatially. We demonstrate this in figure $3 c, 3 d$, where, relative to figure $3 a, 3 b$, a $5 \%$ increase in moth fecundity $\left(f_{\mathrm{m}}\right)$ reverses the coinvasion. Working with a partial differential equation system, Owen and Lewis (2001) demonstrated that spatial contraction versus expansion of an ongoing invasion hinged on the presence of a strong Allee effect in the resource species' growth dynamics. In our model of the Mount St. Helens system, herbivory is most intense (as a proportion of total lupine cover) at the leading edge of the invasion. This dynamic, which induces maximum reduction of seed production under conditions of low plant density, induces an Allee-like effect on the plant's growth rate, suggesting that such a growth mechanism may be necessary for a consumer-induced spatial contraction of a resource species invasion irrespective of the modeling framework used.

Our model can also produce an equilibrium solution in 
a)

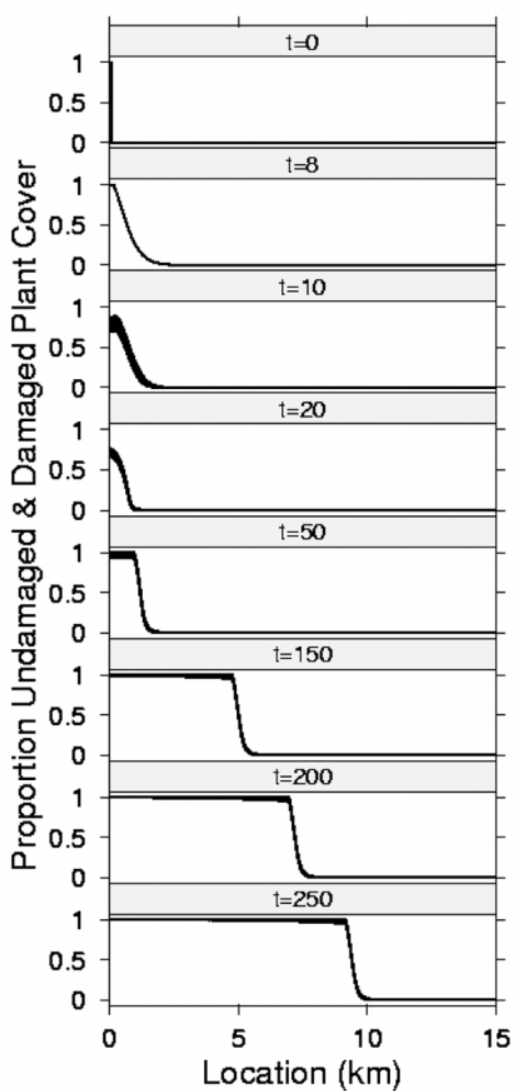

b)

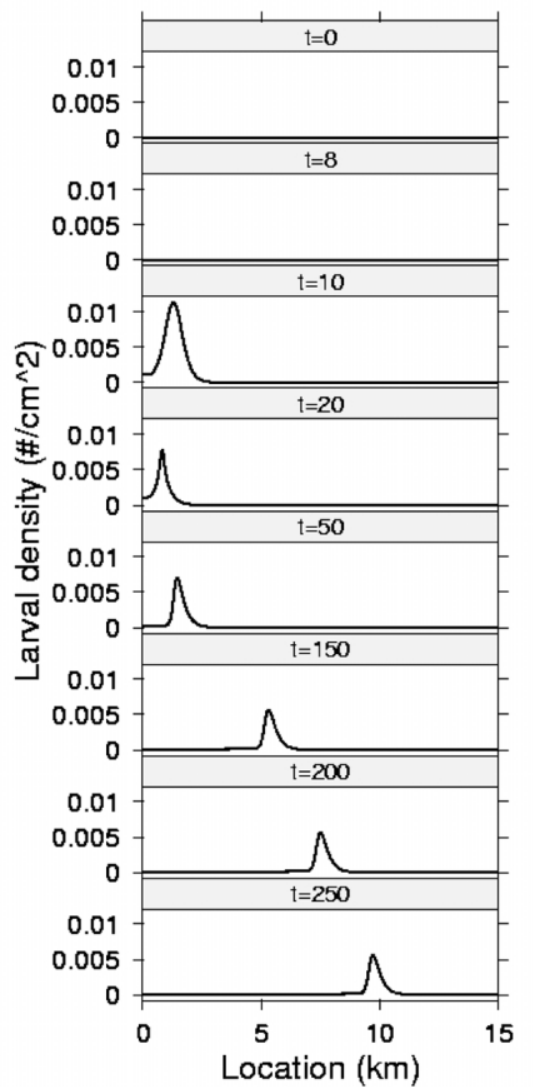

c)
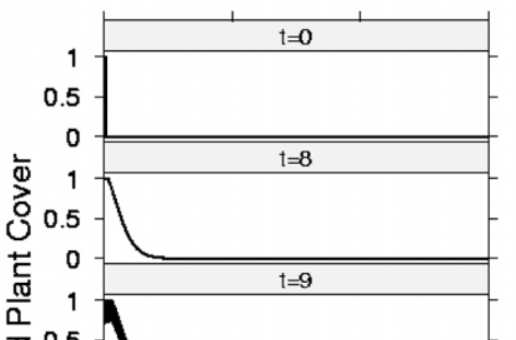

등 0.5 -

(1)

हี

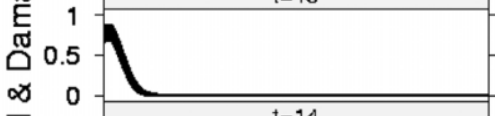

$\infty \quad 0$

g.

0.5

중 0 -

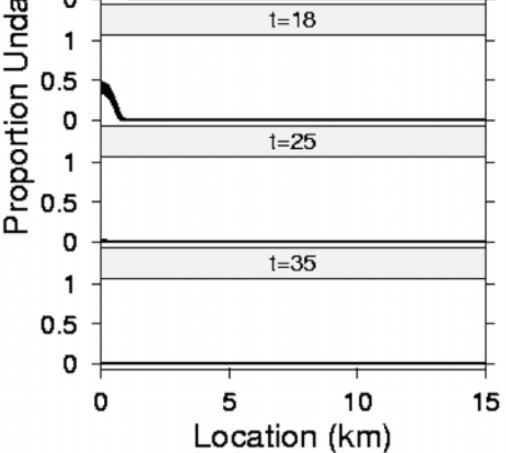

d)

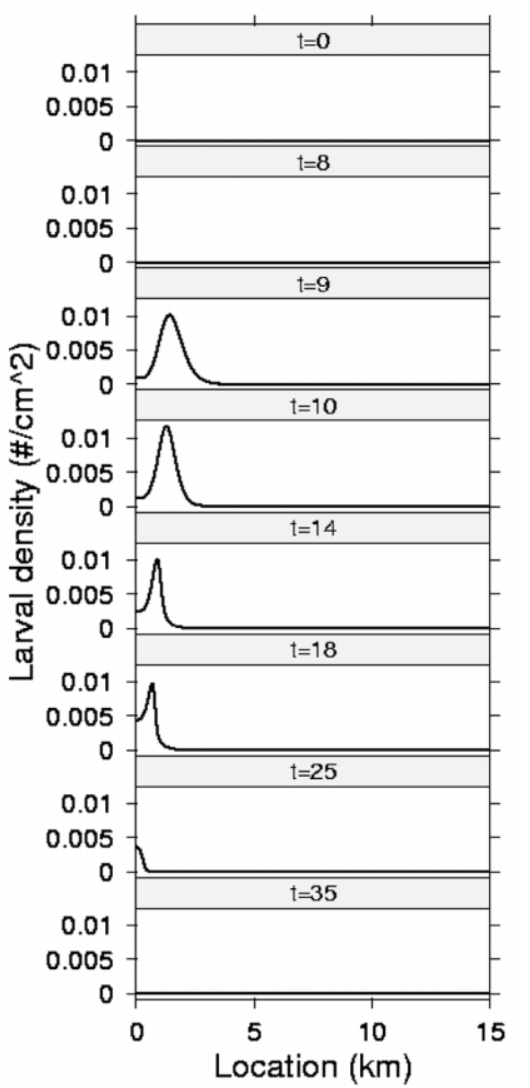

Figure 3: Time course of the Lupinus-Filatima model in equations (16). $a, b$, Summary of the dynamics for a situation in which the coinvasion continues to expand spatially. $c$, $d$, Summary of the spatial extent of the lupine and herbivore populations, respectively, for a situation in which inverse density-dependent herbivory causes the coinvasion to collapse. In $a$ and $c$, the black curve representing $F_{b}$, the proportion of the lupine surface area damaged by herbivores, is stacked on top of a white curve representing $p_{t}$, the undamaged lupine surface area. In $b$ and $d$, the density of Filatima caterpillars $\left(l_{t}\right)$ is given. All parameters are as in table 1 , except that for $a$ and $b, f_{\mathrm{m}}=95$, whereas for $c$ and $d$, $f_{\mathrm{m}}=100$. Herbivores are instantiated into the model at $t_{0}=8$ years. 
a)

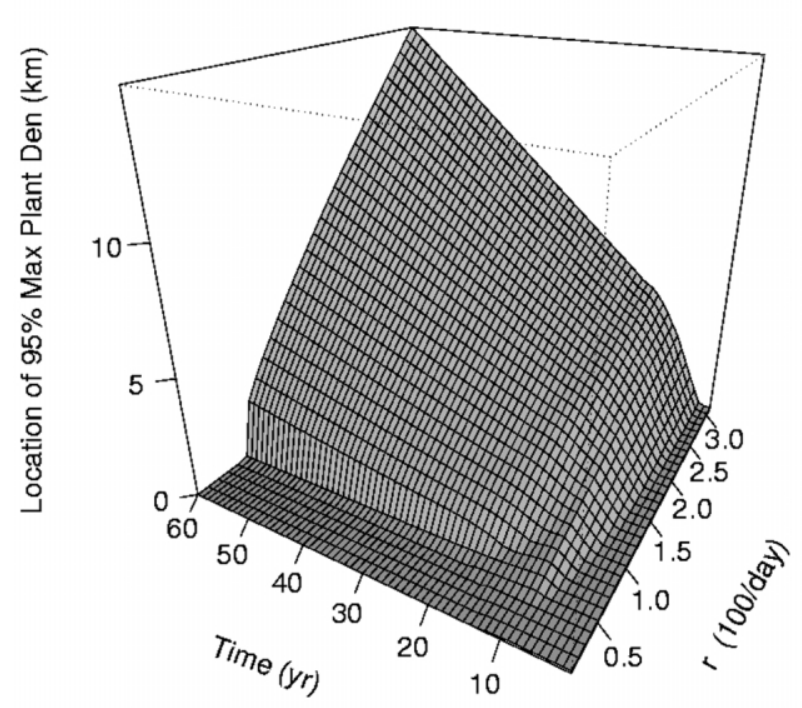

b)

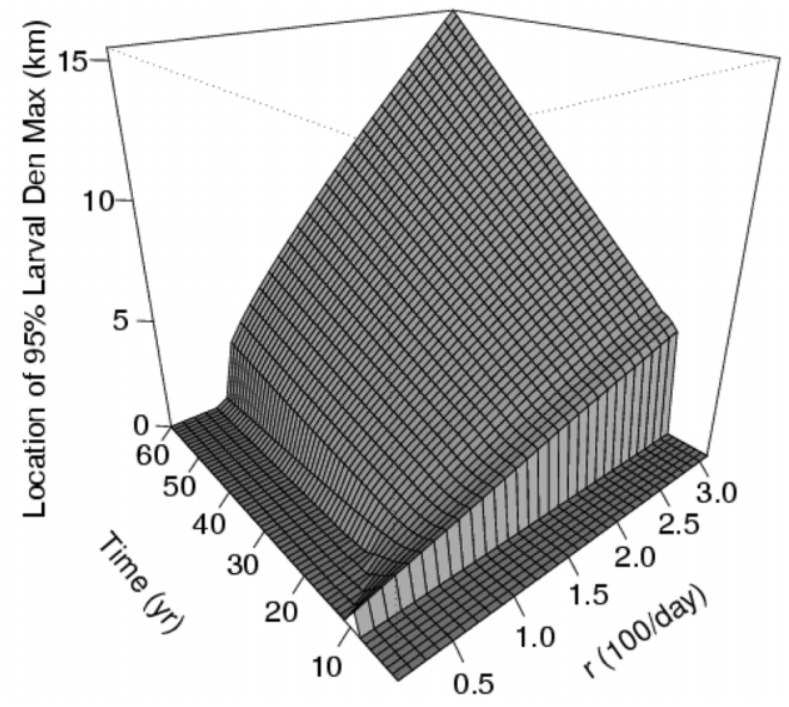

Figure 4: Forwardmost spatial position of high densities of (a) Lupinus and (b) Filatima over the time course of the invasion as a function of $r$, the lupine's intrinsic rate of vegetative growth (rescaled by a factor of 100). Estimates of $r$ from the mid-1990s, earlier in the invasion's history (rescaled $r>2.5\left[\right.$ day $^{-1}$ ]) were sufficient to cause the rapid expansion of the lupine population. More recently obtained estimates of $r$, which are lower (rescaled $r=0.6\left[\right.$ day $\left.^{-1}\right]$ ) and are estimated in the absence of Filatima herbivory but in the presence of feeding damage by other insect herbivores, can cause spatial collapse of the lupine invasion (other parameters as in table 1). To avoid local artifacts or transients, we smooth the surface plot by presenting the spatial location of those densities corresponding to $95 \%$ of the species' respective peak densities.

which herbivory is exactly sufficient to "stall out" the coinvasion, resulting in a stationary patch of lupines (with intense herbivory at its outer margin) that neither expands nor contracts. One such stationary patch results when $f_{\mathrm{m}}$ is increased from its baseline value to $\sim 97$ (app. B in the online edition of the American Naturalist). Changes in other parameters (e.g., $r, a$ ) can accomplish the same effect.

Visualizing the spatiotemporal effects of changes in the model's parameters is a challenging task. One solution is to track the predicted location of particular densities of the lupine and herbivore populations. We opted to follow the time evolution of the forwardmost locations of the lupine and herbivore populations corresponding to $95 \%$ of the species' respective peak densities at each point in a model run. Because Filatima survivorship decreases with increasing lupine density (eq. [12]), Filatima densities tend to be higher under conditions of low lupine density. Thus, the spatial peak in the Filatima population tends to occur farther out along the invasion's trajectory than the spatial peak in the lupine population (i.e., peak herbivore densities are rightshifted relative to maximum lupine cover in fig. 3 and app. B).

Manipulating the vegetative growth rate parameter $r$ provides special insight into the plant-herbivore dynamics because estimates of this parameter are context dependent.
In the absence of herbivory by Filatima, estimates of $r$ from the mid-1990s, earlier in the recolonization process, were about four times as high as comparable measures obtained more recently $\left(r=0.026\right.$ vs. 0.006 day $\left.^{-1}\right)$. The lower estimates of $r$ derive from plots in which Filatima was absent but where several other insect species, representing a range of herbivore guilds, were present. Together with our best estimates of all other parameters (table 1), the distinction between the old and new estimates of $r$ is sufficient to cause a qualitative shift in the dynamics of the coinvasion from rapid expansion to spatial collapse (fig. 4). Thus, the synergistic effects of several insect herbivores will likely be critical to determining the long-term success of the lupine invasion, with only a portion of the story being captured in the model we present here.

The timing of herbivore colonization relative to the start of the lupine invasion also is critical to long-term expansion or collapse of the coinvasion. From our best empirical estimates of the model's parameters, if the herbivores are allowed to colonize shortly after the start of the plant invasion, they can reduce the plants' population growth rate sufficiently to collapse the plant population backward on itself (fig. $5 ; t_{0}<9$ years). In contrast, if the herbivores arrive later, after the lupine population has had more time to establish, then the herbivores have less effect on the lupine 
a)

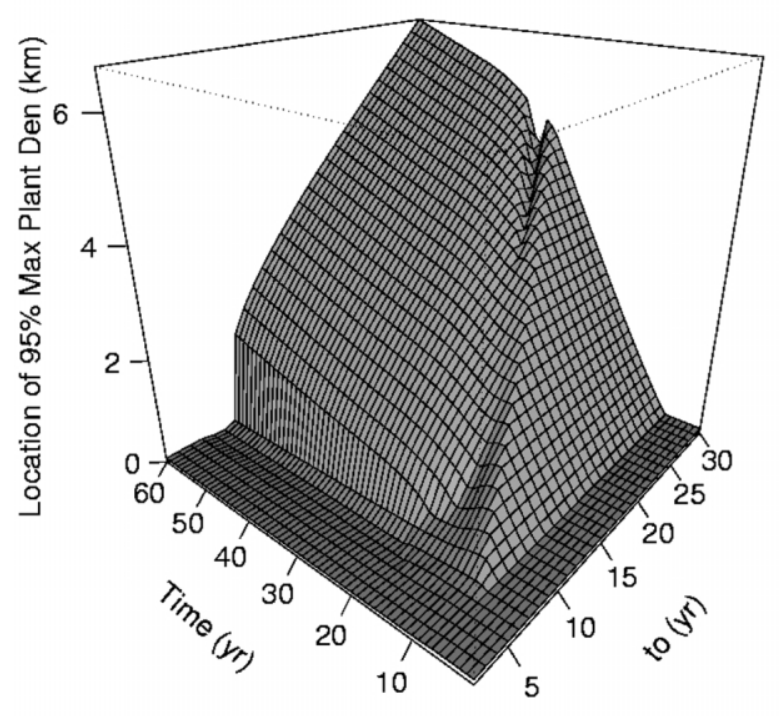

b)

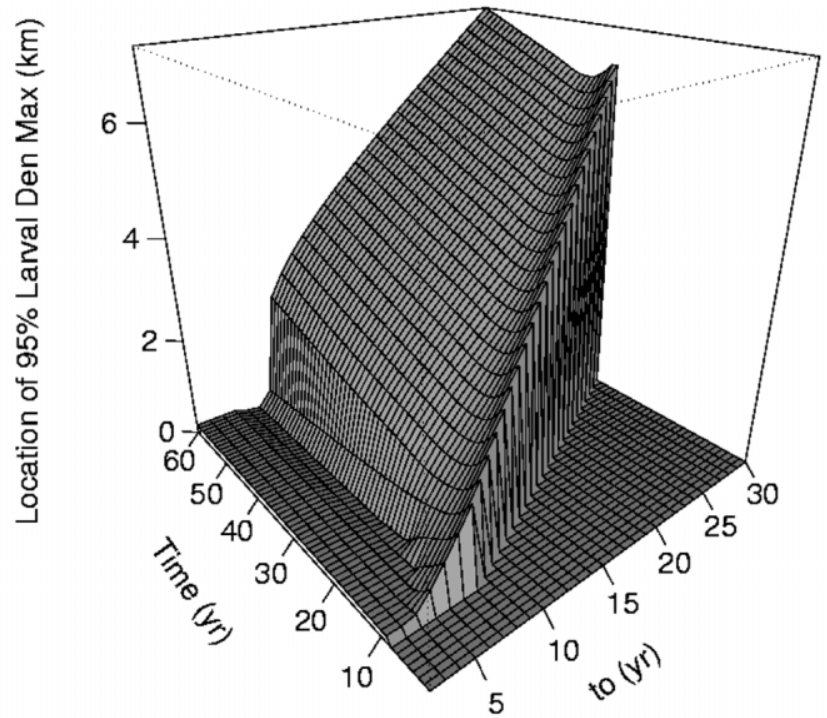

Figure 5: Forwardmost spatial position of high densities of (a) Lupinus and (b) Filatima over the time course of the invasion as a function of the temporal lag between the earlier arrival of the plants and the later arrival of the herbivores. Using our best empirical estimates of the model's parameters, collapse of the lupine population is possible only if the herbivores colonize the system within 8 years after the start of the lupine invasion. For later herbivore arrival times, the caterpillars will slow the advance of the plant invasion and cause a temporary decrease in the spatial extent of high plant densities (the pit that appears just left of center on the surface in $a$ ), but they cannot stop the lupine invasion or cause it to collapse completely. To avoid local artifacts or transients, we smooth the surface plot by presenting the spatial location of those densities corresponding to $95 \%$ of the species' respective peak densities.

invasion. For example, the herbivores may slow or even cause a temporary retreat of the lupine population (fig. 5; $9<t_{0}<17$ years), but they cannot stop its eventual outward spread. Given a sufficiently long time lag between the earlier arrival of the plants and the later arrival of Filatima, herbivore effects on the rate of spread of the plant population are further lessened and take longer to develop. The intensity of these effects depends on where we instantiate the herbivores into the ongoing lupine invasion. We have assumed that herbivores colonize first near the origin of the lupine invasion, because this appears to have been what happened at Mount St. Helens. Allowing the herbivores to instead colonize at the front of the lupine invasion (as would be the case if females actively searched for some correlate of plant quality associated with low-density growth conditions) has quantitative effects on the importance of timing. However, the effect is not overwhelming because we already assume that the herbivores have a greater likelihood of longdistance dispersal (i.e., $\alpha>\beta$ ).

The most striking result related to invasion timing is that there appear to be threshold levels of spatial extent and/or temporal advantage for the plant that together define critical values of invasion momentum, beyond which herbivores are unable to reverse a plant invasion (fig. 6).
Given a sufficiently fast lupine growth rate or a sufficiently long lag before the herbivore arrives, a coinvasion will occur with the herbivores riding the front edge of the invading lupine wave. For slow lupine growth rates and short herbivore lag times, the herbivore collapses the lupine invasion backward, and both species become extinct. For intermediate lupine growth rates and short herbivore lag times, the long-run dynamics of equations (16) involve a single, persistent "stationary patch" like that shown in appendix B. Interestingly, this phenomenon occurs in a finite region of parameter space rather than as a delicately balanced transition between expansion and collapse of the coinvasion (fig. 6). To explore further the consequences of changing parameter values, we conducted a sensitivity analysis of the model's qualitative output (app. C in the online edition of the American Naturalist), which further suggests that the lupine-Filatima system falls very close to the boundary separating successful and failed invasions. However, we note that, in the sensitivity analysis, the most likely qualitative outcome was a stationary patch, and the least likely outcome was a successful coinvasion, in contrast with the predictions emerging from our best estimates of the parameters (fig. 6). 


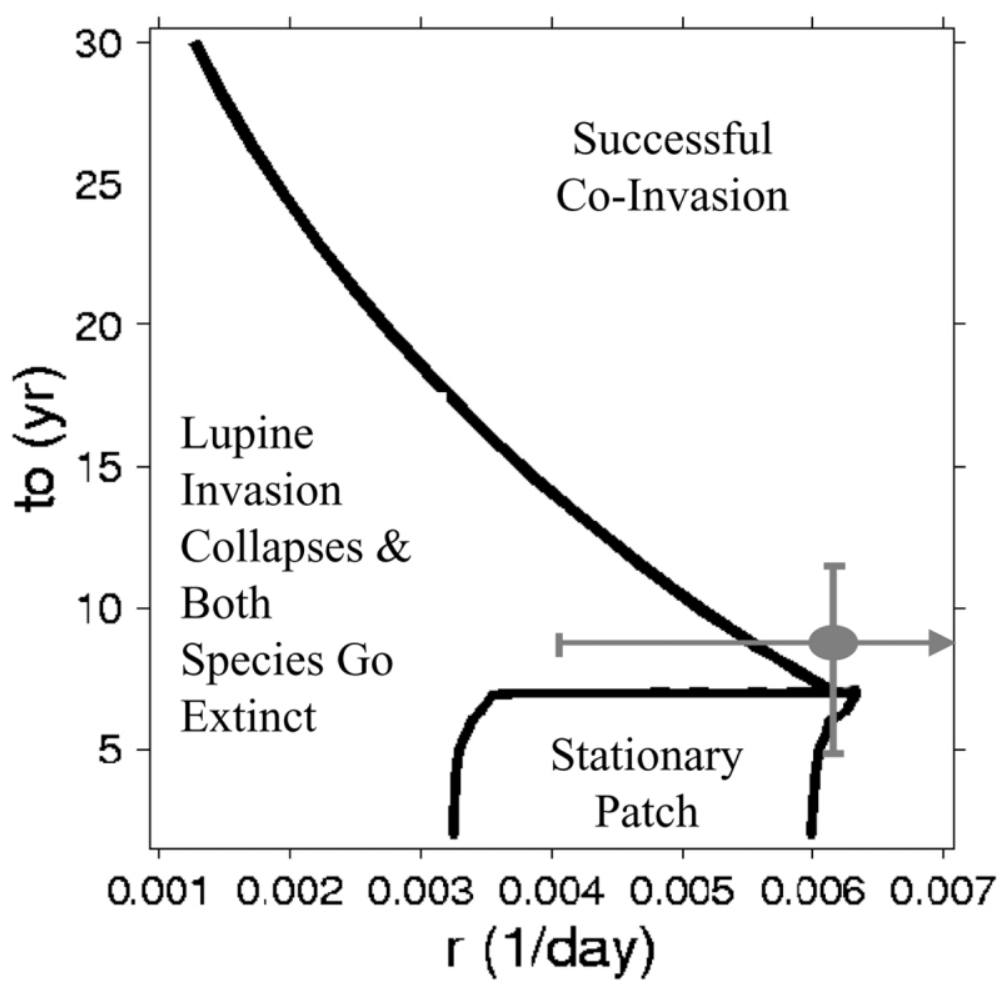

Figure 6: Qualitative dynamics of the lupine-herbivore model in $r \times t_{0}$ parameter space. Three classes of long-run dynamics are possible. For slow lupine growth rates with short lag times before herbivore arrival, we observed contracting patch dynamics and collapse of the plant-herbivore system (as in fig. $3 c, 3 d$ ). For faster lupine growth rates, we observed forward-spreading coinvasion dynamics (as in fig. $3 a$, $3 b$ ). For intermediate lupine growth rates but short delays in herbivore arrival, a single stationary patch emerged with coexisting lupines and herbivores (as in app. B). We fixed the boundaries of this region of parameter space as those parameter combinations for which the invasive front of the lupine population moved by less than $0.5 \mathrm{~m} \mathrm{year}^{-1}$. From table 1 , the best estimate and range of the delay $t_{0}$ and the best estimate $( \pm 1 \mathrm{SE})$ of $r$ are overlaid in gray.

\section{Discussion}

The lupine-Filatima system at Mount St. Helens appears perched very close to the dynamic threshold separating conditions for spatial advance and spatial retreat of the plantherbivore coinvasion. To the extent that our mathematical representation captures the main components of the plantherbivore coinvasion, our analyses suggest that destructive herbivory by Filatima is quite capable of demonstrably slowing the rate of spatial spread by the lupine population. Indeed, we know from field observations and experiments (Bishop 1996, 2002; Fagan and Bishop 2000; Fagan et al. 2004; Bishop et al. 2005) that Filatima causes tremendous reductions in lupine seed production, and we have witnessed herbivore-induced patch shrinkage that represents invasion failure on a small scale (Bishop et al. 2005). However, our mathematical analyses here suggest that even these prodigious effects are insufficient to engender a long-term, broadscale spatial contraction of the lupine population, but the herbivores' effects are close to doing so. If all other parameters of the model are held at our best estimates (table 1), relatively small changes in any of several parameters reflecting life-history traits or attributes of the plant-herbivore interaction (e.g., $r, a, f_{\mathrm{m}}$ ) would allow a modified Filatimalike herbivore to reverse the invasion of a lupine-like plant (fig. $3 c, 3 d$; figs. 4,5 ). Interestingly, something as simple as the timing of herbivore arrival would also switch the system between spread and collapse of the coinvasion (fig. 6). In this discussion, we focus first on the specific implications of rate of spread of the plant-herbivore coinvasion for primary succession at Mount St. Helens and then on the more general issue of invasion timing.

\section{Insect Herbivory at Mount St. Helens: Inverse Density Dependence and Its Successional Effects}

The lupine-Filatima system at Mount St. Helens deviates from conventional wisdom about terrestrial plant-herbivore interactions in several important respects. The longterm pattern of inverse density-dependent herbivory (fig. 1) constitutes perhaps the most striking exception to the 
predictions that the major theories of plant-herbivore interactions would make about the system. Both the resource concentration hypothesis (Root 1973) and plant apparency theory (Feeny 1976; Rhoads and Cates 1976) would predict greater levels of herbivory in the core region, where lupine patches exist at higher density, offer much greater biomass, and are far more persistent. All the more surprising is that the conspicuous inverse density-dependent herbivory is not restricted to feeding by Filatima. Remarkably, the activities of at least four different herbivore species (representing three distinct feeding guilds) are effectively confined to low-density areas of lupine, where they cause local spatial collapse of lupine patches, a shifting mosaic of small patches, and extreme fluctuation in percent cover (del Moral 2000b; Bishop 2002; Bishop et al. 2005). Inverse density dependence appears critical to the coinvasion dynamics in this system because the herbivores' enhanced performance under conditions of low lupine density induces a strong Allee effect for the plant, a trait that has been shown necessary to reverse a traveling wave of invasion by a resource species in partial differential equation models (Owen and Lewis 2001). Negative relationships between host density and herbivory are known in other plant-herbivore systems, but the underlying mechanisms in any particular case remain obscure (Thompson and Price 1977; Courtney and Courtney 1982; Courtney 1986; Kunin 1999). Revealing the mechanisms that underlie the persistent patterns of herbivory observed at Mount St. Helens will require experimental manipulation, such as our ongoing studies that factorially manipulate soil nutrients and natural enemies.

It is worth comparing results from this model of lupine spatial spread with the far slower spread speeds presented in earlier work. In Fagan and Bishop (2000), we adopted a reaction diffusion framework where the diffusion coefficient was estimated from the recruitment locations of first-generation offspring of lupines growing under ultralow densities (so parentage could be assured). This approach essentially provided an estimate only of "local" spread because our searches for recruiting plants were restricted to $\sim 20-\mathrm{m}$ radii around parent plants. Thus, the model of Fagan and Bishop (2000) yielded information on how quickly an outlying patch of lupine should expand, approximately $4 \mathrm{~m}_{\text {year }}{ }^{-1}$. In contrast, the current model, which yields spread speeds of $\sim 40 \mathrm{~m} \mathrm{year}^{-1}$ (fig. $3 a, 3 b$ ), adopts an integrodifference equation framework with assumed rather than estimated exponential kernels. The coefficient governing the lupine's kernel is based on our knowledge that long-distance seed dispersal events (e.g., $>100 \mathrm{~m}$ ) do occur but are relatively rare (Wood and del Moral 2000). The framework we present here is thus a model of population-level rather than patch-level spread. Although our model's predictions (e.g., spread over $\sim 25$ years of $\sim 1,000 \mathrm{~m}$ ) are likely conservative because we lack good measures of very long distance dispersal, the general results match up well with information gleaned from a recent survey of the entire pumice plains region (J. G. Bishop and J. Apple, unpublished data).

Understanding the broad importance of lupine's herbivore-mediated absence from so much of this landscape requires an overview of lupines' role in successional dynamics at Mount St. Helens. Soon after lupines' initial colonization of the volcanically devastated pumice plain, ecologists predicted that lupines would have major effects on the successional development because they are nitrogen fixers, have a temporal advantage, and can colonize a great diversity of sites. These predictions about the importance of lupine to local community development have proved accurate. For example, lupines accelerated soil development through direct nutrient and organic matter input, trapping of windblown debris and propagules, attraction of insects that ultimately die in situ, and attraction of animal dispersal vectors that transport seeds and microorganisms (Morris and Wood 1989; del Moral and Rozzell, forthcoming). Soils under lupines have much higher levels of total N, organic matter, and microbial activity than do adjacent bare areas (Halvorson et al. 1991, 1992; Halvorson and Smith 1995; Fagan et al. 2004). Furthermore, experiments demonstrate a net positive effect of lupines on growth of ruderal plant species (Morris and Wood 1989; Titus and del Moral 1998), although these species may have to wait for lupines to die to take advantage of particular sites. Recent surveys demonstrated that percent cover of other plant species was higher within lupine patches than outside them and that species composition differed substantially inside and outside lupine patches (del Moral and Rozzell, forthcoming). Indeed, nutrientresponsive species such as the grass Agrostis pallens are so common in core-type lupine patches that the region was, at one point, predicted to transition successionally into high-elevation grasslands, although grass-eating herbivores (elk and grasshoppers) have put an end to this idea (C. Crisafulli, personal communication).

The presence of lupines is clearly important to community development at Mount St. Helens. By extension, then, insect herbivory that has prevented or at least delayed lupine colonization of large portions of the pumice plain has indirectly determined the course of primary succession by hindering the early stages of soil formation and changing the floristic trajectory. This conclusion, that insect herbivores are helping to shape the pace and pattern of primary succession at Mount St. Helens, runs counter to the general theory of primary succession (Walker and del Moral 2003; see also app. D in the online edition of the American Naturalist). We suspect that insect herbivores may be more important to succession in disturbed landscapes than is commonly appreciated. The lesson of this 
model, and of the Mount St. Helens system more generally, is that gauging such importance can require a deliberate focus on issues relating to the absence of a species from a landscape rather than its presence. The latter is far easier to grapple with conceptually.

\section{The Importance of Invasion Timing and Its Implications for Biological Control}

Timing appears to play a critical role in determining the spatial success of the lupine invasion at Mount St. Helens. In our model, we manipulated the relative timing of initial colonization by the plant and the herbivore via the time lag parameter $t_{0}$ and found three qualitatively different cases of results: a persistent stationary patch, spatial collapse leading to extinction, and successful coinvasion (fig. 6). Case 1, the stationary patch, is an unusual result in this model because it occurs for a finite region of parameter space rather than as a transition between successful and failed coinvasions. However, comparable results are known from certain activator-inhibitor-type neural-field models (Amari 1977; Coombes et al. 2003). In our system, the stationary-patch result occurs when overdispersal by the herbivore and its increased success under conditions of low lupine density are sufficient to contain the lupine population but insufficient to collapse the lupine patch altogether. Case 2, extinction of both species, occurs when the lupine grows slowly and/or the lag time until herbivore arrival is short. In these cases, herbivore damage is sufficient to collapse the lupine patch in on itself, thereby eliminating the herbivores' food resource. Note, however, that a linearization of equations (16) at the origin (not shown) yields an expression with a positive growth term for the lupine but no growth for the herbivore. Thus, the origin is not a stable equilibrium in this model, and the lupine can never become completely extinct in an analytical sense (although the herbivore can). From a numerical perspective, for parameter combinations in which the lupine patch collapses backward, the herbivore drives the lupine down to nonbiological levels (e.g., $10^{-14} \%$ cover), at which time the herbivore becomes extinct and the lupine recovers. This clearly constitutes an "attofox" numerical result (e.g., Mollison 1991), and for our biological purposes, we treat this case as extinction of both plant and herbivore.

For case 3, successful coinvasion, small changes in the time lag parameter differentiate scenarios in which herbivory is sufficiently pervasive to collapse the plant invasion back on itself from those in which the plant population continues to expand spatially. In other words, given a sufficient "head start" before herbivore colonization (or, alternatively, given a sufficient spatial extent), the lupine invasion was not reversible in our model. Herbivores could slow the spread of the lupines, sometimes greatly so, but late-arriving herbivores could not turn the plant invasion backward. In Fagan and Bishop (2000) we described this phenomenon as "invasion momentum," noting that in a simpler model of lupine spread featuring a linear growth term, several years of herbivore-free growth will allow the lupine population to spread rapidly for several years even after the herbivores' arrival. The present model demonstrates that the phenomenon of invasion momentum also occurs under conditions of density-dependent growth for the plants. In the field, the mechanism underlying such invasion momentum involves the enormous reproductive potential of the large, high-density core region patches of lupine where lupine seed production regularly exceeds thousands of seeds per square meter (Bishop 1996, 2002; Fagan and Bishop 2000). Unlike the intense inverse density dependence (which, though not unknown, is atypical of herbivore-plant interactions at large), the potential for massive seed rain from regions of high plant density is a phenomenon that likely generalizes broadly to other coinvasions. In contrast to the Mt. St. Helens system, theory suggests that direct density dependence, in which intensive herbivory falls on high-density "cores" of an invading plant, will be insufficient to slow or reverse the spatial spread of an invading plant (Owen and Lewis 2001). However, such herbivory can certainly influence the standing crop of invasive plants (Fagan et al. 2002).

Our conclusions about the crucial role of timing and invasion momentum within the lupine-herbivore system at Mount St. Helens echo recent discussions of the importance of timing within the invasion biology literature (Gressel et al. 1996; Fagan et al. 2002; von Holle et al. 2003; Simberloff 2003). A key message emerging from that body of research concerns the importance of taking management actions against invasive pest species very soon after their discovery because small patches comprising few individuals are far easier to eliminate through chemical or mechanical means than are large patches. Because of invasion momentum, delays of even a few years in the application of control methods against a population of an invasive pest species could take years of dogged mechanical removal efforts or pesticide applications to surmount.

Our work here suggests that, when permitted by practical issues associated with early detection of invading pests, the advantages of early management actions are likely to extend to biological control techniques as well. Consider the similarities between the lupine-herbivore system and a weedbiocontrol agent system. As a colonizer of disturbed habitats, native prairie lupines exhibit some, but not all, of the suite of life-history characteristics that are typically associated with weedy plant species (e.g., nitrogen fixing, fast development rate). Likewise, Filatima possesses many of the characteristics that are often sought after in effective biocontrol agents: it is a highly specialized herbivore that can 
successfully locate, attack, and have substantial negative effect on small patches of its host plant. If the lupine were a weed whose spread we sought to limit, early introduction of Filatima as a biocontrol agent would clearly be a key to the success of our management actions. This would be true whether the goal was to collapse the weed population or, more plausibly, to slow the spatial spread rate of the weed (fig. 5). The unfortunate reality, of course, is that it may be difficult to convince managers to expend resources on an invading species that is not yet a pest.

\section{Conclusions}

Our model suggests that chance events have played a strong role in shaping the successional trajectory of Mount St. Helens. In particular, the timing of colonization by lupine relative to the onset of herbivory appears to have been critical to the initial success and subsequent spread of the coinvasion. We believe that the lupine-Filatima system makes a good case for the importance of insect herbivory during succession, but when and where herbivory occurs (i.e., early vs. late and low- vs. high-density areas) may be at least as important as how much herbivory occurs.

\section{Acknowledgments}

We are indebted to M. Owen for crucial insights, helpful discussions, double-checking the Matlab code, and unflagging interest in the havoc that little bugs can cause for purple plants. This effort would not have been possible without the support of the National Science Foundation through its Mathematical Biology and Ecological Studies programs (awards NSF OCE-9973212, DEB-9973518, DEB-0235692, and DEB-0089843). The University of Maryland, Washington State University-Vancouver, and the Banff International Research Station for Mathematical Innovation and Discovery provided additional support. M.L. acknowledges support from Mathematics of Information Technology and Complex Systems Canada, a Natural Sciences and Engineering Research Council operating grant, a Contract Research Organisation grant, and a Canada Research Chair. For identifying the lupine moths, we are indebted to D. Adamski (Filatima), L. Crabo (Euxoa), and A. Solis (Staudingeria).

\section{Literature Cited}

Amari, S. 1977. Dynamics of pattern formation in lateral-inhibition type neural fields. Biological Cybernetics 27:77-87.

Andow, D. A., P. M. Kareiva, S. A. Levin, and A. Okubo. 1990. Spread of invading organisms. Landscape Ecology 4:177-188.

Bishop, J. G. 1996. Demographic and population genetic variation during colonization by the herb Lupinus lepidus on Mount St. Helens. PhD diss. University of Washington, Seattle.

2002. Early primary succession on Mount St. Helens: the impact of insect herbivores on colonizing lupines. Ecology 83:191202.

Bishop, J. G., and D. W. Schemske. 1998. Variation in flowering phenology and its consequences for lupines colonizing Mount St. Helens. Ecology 79:534-546.

Bishop, J. G., W. F. Fagan, J. D. Schade, and C. M. Crisafulli. 2005. Causes and consequences of herbivory on prairie lupine (Lupinus lepidus) in early primary succession. Pages 151-161 in V. H. Dale, F. Swanson, and C. M. Crisafulli, eds. Ecological responses to the 1980 eruptions of Mount St. Helens. Springer, New York.

Broadbent, S. R., and D. G. Kendall. 1953. The random walk of Trichostrongylus retortaeformis. Biometrics 9:460-466.

Caswell, H., R. Lensink, and M. G. Neubert. 2003. Demography and dispersal: life table response experiments for invasion speed. Ecology 84:1968-1978.

Clark, J. S., C. Fastie, G. Hurtt, S. T. Jackson, C. Johnson, G. A. King, M. Lewis, et al. 1998. Reid's paradox of rapid plant migration: dispersal theory and interpretation of paleoecological records. BioScience 48:13-24.

Coombes, S., G. J. Lord, and M. R. Owen. 2003. Waves and bumps in neuronal networks with axo-dendritic synaptic interactions. Physica D 178:219-241.

Courtney, S. P. 1986. The ecology of pierid butterflies: dynamics and interactions. Advances in Ecological Research 15:51-131.

Courtney, S. P., and S. Courtney. 1982. The "edge effect" in butterfly oviposition: causality in Anthocaris cardamines and related species. Ecological Entomology 7:131-137.

del Moral, R. 2000a. Local species turnover on Mount St. Helens. Pages 195-197 in P. White, ed. Proceedings of the 41st Symposium of the International Union of Vegetation Scientists.

-2000b. Succession and species turnover on Mount St. Helens, Washington. Acta Phytogeographica Suecica 85:53-62.

del Moral, R., and L. R. Rozzell. Forthcoming. Long-term facilitation of vegetation by Lupinus lepidus on Mount St. Helens. Plant Ecology.

Dunbar, S. R. 1983. Traveling wave solutions of diffusive LotkaVolterra equations. Journal of Mathematical Biology 17:11-32.

Edwards, J. S., and R. Sugg. 1993. Arthropod fallout as a resource in the recolonization of Mount St. Helens. Ecology 74:954-958.

Elser, J. J., W. F. Fagan, R. F. Denno, D. R. Dobberfuhl, A. Folarin, A. Huberty, S. Interlandi, et al. 2000. Nutritional constraints in terrestrial and freshwater food webs. Nature 408:578-580.

Fagan, W. F., and J. G. Bishop. 2000. Trophic interactions during primary succession: herbivores slow a plant reinvasion at Mount St. Helens. American Naturalist 155:238-251.

Fagan, W. F., M. A. Lewis, M. G. Neubert, and P. van den Driessche. 2002. Invasion theory and biological control. Ecology Letters 5:110.

Fagan, W. F., J. G. Bishop, and J. D. Schade. 2004. Spatially structured herbivory and primary succession at Mount St. Helens: field surveys and experimental growth studies suggest a role for nutrients. Ecological Entomology 29:398-409.

Feeny, P. P. 1976. Plant apparency and chemical defense. Recent Advances in Phytochemistry 10:1-40.

Fisher, R. A. 1937. The wave of advance of advantageous genes. Annals of Eugenics 7:353-369.

Gressel, J., L. Segel, and J. K. Ransom. 1996. Managing the delay of evolution of herbicide resistance in parasitic weeds. International Journal of Pest Management 42:113-129.

Hajek, A. E., J. S. Elkinton, and J. J. Witcosky. 1996. Introduction 
and spread of the fungal pathogen Entomophaga maimaiga (Zygomycetes: Entomophthorales) along the leading edge of gypsy moth (Lepidoptera: Lymantriidae) spread. Environmental Entomology 25:1235-1247.

Halvorson, J. J., and J. L. Smith. 1995. Decomposition of lupine biomass by soil microorganisms in developing Mount St. Helens pyroclastic soils. Soil Biology and Biochemistry 27:983-992.

Halvorson, J. J., J. L. Smith, and E. H. Franz. 1991. Lupine influence on soil carbon, nitrogen and microbial activity in developing ecosystems at Mount St. Helens. Oecologia (Berlin) 87:162-170.

Halvorson, J. J., E. H. Franz, J. L. Smith, and R. A. Black. 1992. Nitrogenase activity, nitrogen fixation, and nitrogen inputs by lupines at Mount St. Helens. Ecology 73:87-98.

Harper, J. L. 1977. Population biology of plants. Academic Press, New York.

Hassell, M. P. 1978. The dynamics of arthropod predator-prey systems. Princeton University Press, Princeton, NJ.

Kerle, E. A. 1985. The ecology of lupines in Crater Lake National Park. MS thesis. Oregon State University, Corvallis.

Kot, M. 2001. Elements of mathematical ecology. Cambridge University Press, Cambridge.

Kot, M., M. A. Lewis, and P. van den Driessche. 1996. Dispersal data and the spread of invading organisms. Ecology 77:2027-2042.

Kunin, W. E. 1999. Patterns of herbivore incidence on experimental arrays and field populations of ragwort, Senecio jacobea. Oikos 84: $515-525$.

Lensink, R. 1997. Range expansion of raptors in Britain and the Netherlands since the 1960s: testing an individual-based diffusion model. Journal of Animal Ecology 66:811-826.

Louda, S. M., D. Kendall, J. Connor, and D. Simberloff. 1997. Ecological effects of an insect introduced for the biological control of weeds. Science 277:1088-1090.

Lubina, J., and S. Levin. 1988. The spread of a reinvading species: range expansion of the California sea otter. American Naturalist 131:526-543.

Mack, R. N. 1981. Invasion of Bromus tectorum L. into western North America: an ecological chronicle. Agro-Ecosystems 7:145-165.

McCook, L. J. 1994. Understanding ecological community succession: causal models and theories, a review. Vegetatio 110:115-147.

Mollison, D. 1991. Dependence of epidemic and population velocities on basic parameters. Mathematical Biosciences 107:255-287.

Morris, W. F., and D. M. Wood. 1989. The role of Lupinus lepidus in succession on Mount St. Helens: facilitation or inhibition? Ecology 70:697-703.

Neubert, M. G., and H. Caswell. 2000. Demography and dispersal: calculation and sensitivity analysis of invasion speed for structured populations. Ecology 81:1613-1628.

Neubert, M. G., M. Kot, and M. A. Lewis. 1995. Dispersal and pattern formation in a discrete-time predator-prey model. Theoretical Population Biology 48:7-43.

- 2000. Invasion speeds in fluctuating environments. Proceedings of the Royal Society of London B 267:1603-1610.

Oetting, R. D. 1977. Immature stages and biology of Chionodes psiloptera, a pest in bluegrass seed fields. Pan-Pacific Entomologist 53:258-268.

Okubo, A., P. K. Maini, M. H. Williamson, and J. D. Murray. 1989. On the spatial spread of the grey squirrel in Britain. Proceedings of the Royal Society of London B 238:113-125.

Owen, M. R., and M. A. Lewis. 2001. How predation can slow, stop or reverse a prey invasion. Bulletin of Mathematical Biology 63: 655-684.

Parker, I. M. 2000. Invasion dynamics of Cytisus scoparius: a matrix model approach. Ecological Applications 10:726-743.

Parker, I. M., and K. A. Haubensak. 2002. Comparative pollinator limitation of two non-native shrubs: do mutualisms influence invasions? Oecologia (Berlin) 130:250-258.

Petrovskii, S. V., A. Y. Morozov, and E. Venturino. 2002. Allee effect makes possible patchy invasion in a predator-prey system. Ecology Letters 5:345-352.

Rhoads, D. F., and R. G. Cates. 1976. Toward a general theory of plant antiherbivore chemistry. Recent Advances in Phytochemistry 10:168-213.

Root, R. B. 1973. Organization of a plant-arthropod association in simple and diverse habitats: the fauna of collards. Ecological Monographs 43:95-124.

Scriber, J. M., and P. Feeny. 1979. Growth of herbivorous caterpillars in relation to feeding specialization and to the growth form of their food plants. Ecology 60:829-850.

Sharov, A. A., D. Leonard, A. M. Liebhold, E. A. Roberts, and W. Dickerson. 2002. "Slow the spread": a national program to contain the gypsy moth. Journal of Forestry 100:30-35.

Sherratt, J. A., M. A. Lewis, and A. C. Fowler. 1995. Ecological chaos in the wake of invasion. Proceedings of the National Academy of Sciences of the USA 92:2524-2528.

Shigesada, N., K. Kawasaki, and E. Teramoto. 1986. Traveling periodic waves in heterogeneous environments. Theoretical Population Biology 30:143-160.

Silvertown, J. W., and J. Lovett-Doust. 1993. Introduction to plant population biology. Blackwell Scientific, London.

Simberloff, D. 2003. Eradication-preventing invasions at the outset. Weed Science 51:247-253.

Skellam, J. 1951. Random dispersal in theoretical populations. Biometrika 38:196-218.

Thompson, J. N., and P. W. Price. 1977. Plant plasticity, phenology, and herbivore dispersion: wild parsnip and the parsnip webworm. Ecology 58:1112-1119.

Titus, J. H., and R. del Moral. 1998. The role of mycorrhizal fungi and microsites in primary succession on Mount St. Helens. American Journal of Botany 85:370-375.

van den Bosch, F., J. A. J. Metz, and O. Diekmann. 1990. The velocity of spatial population expansion. Journal of Mathematical Biology 28:529-565.

Veit, R. R., and M. A. Lewis 1996. Dispersal, population growth, and the Allee effect: dynamics of the house finch invasion of eastern North America. American Naturalist 148:255-274.

von Holle, B., H. R. Delcourt, and D. Simberloff. 2003. The importance of biological inertia in plant community resistance to invasion. Journal of Vegetation Science 14:425-432.

Walker, L. R., and R. del Moral. 2003. Primary succession and ecosystem rehabilitation. Cambridge University Press, Cambridge.

Wood, D. M., and R. del Moral. 1987. Mechanisms of early primary succession in subalpine habitats on Mount St. Helens. Ecology 68: 780-790.

- 2000. Seed rain during early primary succession on Mount St. Helens, Washington. Madroño 47:1-9.

Associate Editor: Benjamin M. Bolker Editor: Donald L. DeAngelis 